\title{
The Study of Economic and Social Status of Iranian female-headed households: a secondary analysis
}

\author{
Ahmad Dorahaki ${ }^{1 *}$, Reza Noubahkt ${ }^{2}$ \\ 1. Faculty of Social Sciences, Allameh Tabataba'i University, Tehran, Iran \\ 2. Faculty of Social and Economic Sciences, Payame Noor University, Iran
}

Received: 27 May 2021

Accepted for publication: 15 June 2020

[EPub a head of print-17 July 2021]

Payesh: 2021; 20 (4): 427- 437

\begin{abstract}
Objective (s): In Iran, recent official data show a growing trend in the number of female-headed households. On the other hand, female-headed households are known as vulnerable groups in society that need attention in various social, economic and health aspects.

Methods: This study used the secondary analysis of the combined file of household characteristics and personal characteristics of $2 \%$ of the general population and housing census data of 2016, which was collected by the Statistics Center of Iran. The extracted variables analyzed by individual level included age, number of children, marital status, place of residence, migration status, education, literacy, working status and household level variables included number of household members, living area measured in square meters, residential house ownership and type of residential house.

Results: Based on the analysis of $2 \%$ of the census data, female-headed households constitute $12.5 \%$ of the Iranian heads of households. The percentage of caretaker is significantly related to age and about $50 \%$ of women-headed households are 60 years and older. Marital status also indicates that $68 \%$ of the reasons for headed women are due to the death of the husband and $12 \%$ are due to divorce. Also, $14 \%$ of women who have a husband are heads of households. $44 \%$ of women-headed households are living in single family, and female-headed households are less mobile than male-headed households. Literacy is significantly related to gender and $54 \%$ of female-headed households are illiterate. Only $14 \%$ of women -headed households are employed. $24.8 \%$ of women -headed households live in mortgaged and rented houses and about $7 \%$ of them live in houses with 40 square meters and less.

Conclusion: According to the results of the present study, it can be said that the leading challenges of women -headed households follow three cultural dimensions such as issues related to widowhood and barriers to remarriage, economic dimensions such as housing and employment and demographic issues such as living in single family. Policy-making is necessary in all three dimensions.
\end{abstract}

Key Words: Women Heads of Household, Census, Economic and Social Status, Iran

\footnotetext{
* Corresponding author: Faculty of Social Sciences, Allameh Tabataba'i University, Tehran, Iran

E-mail: Ahmaddorahaki@gmail.com
} 


\title{
بررسى وضعيت اقتصادى و اجتماعى زنان سريرست خانوار ايرانى: يك آناليز ثانويه
}

\author{
احمد دراهكى '*، رضا نوبخت

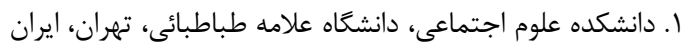

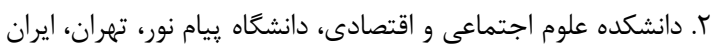

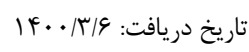

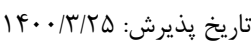

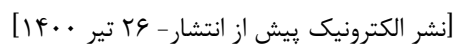

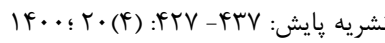

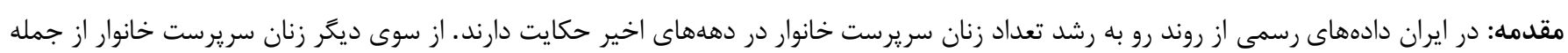

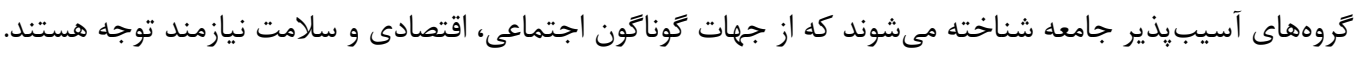

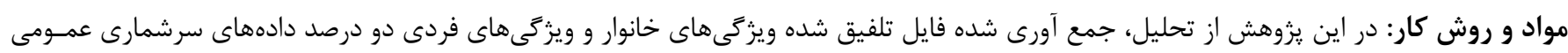

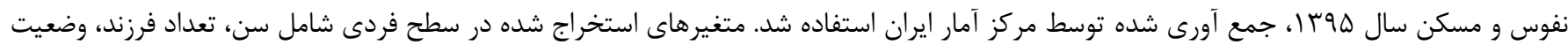

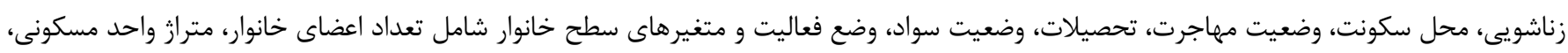

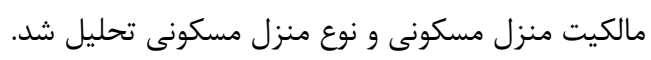

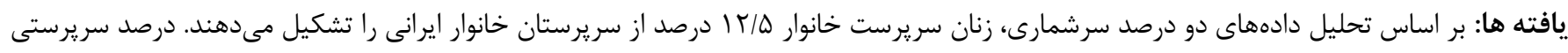

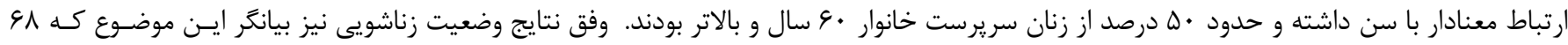

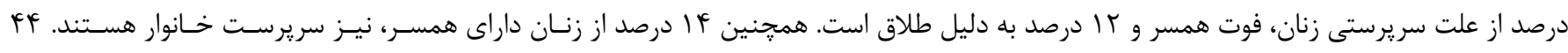

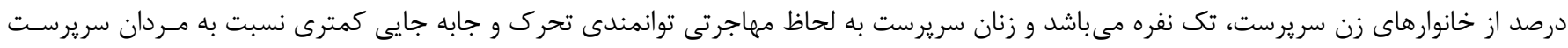

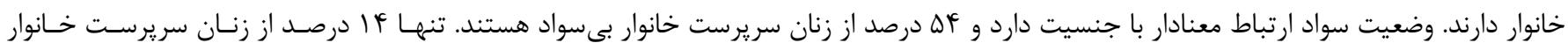

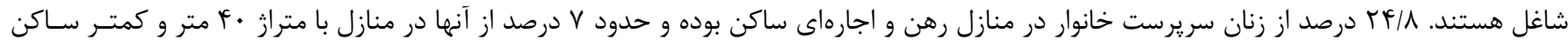

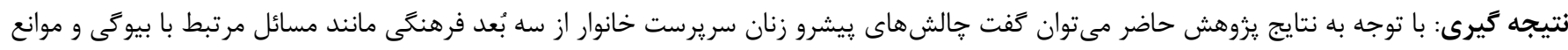

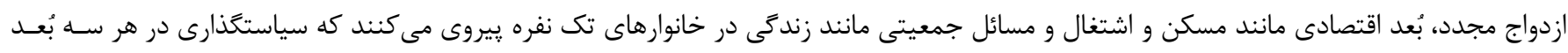


نقش هاى جندكانه بعد از فقدان همسرشان مىشوند. آنهـا مجبورنـــــا

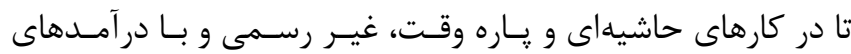

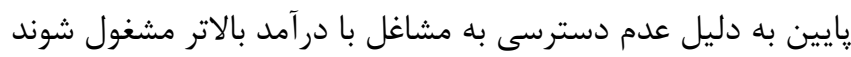

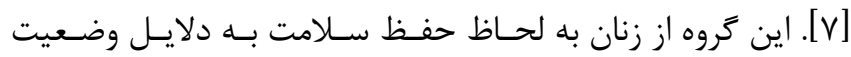

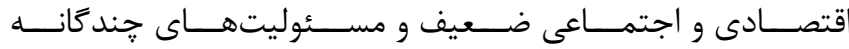

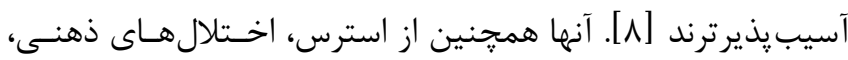

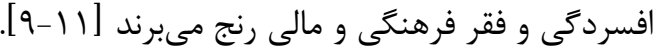

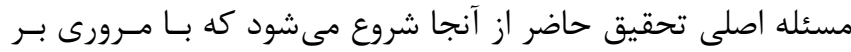

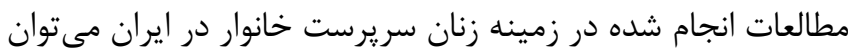
آنها را به سه دسته كلى تقسيمبندى كرد: ا- تحقيقات آمـارى كـهـ

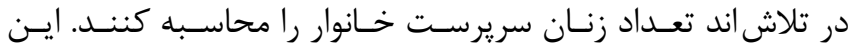

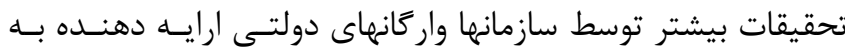

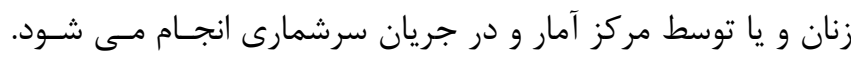

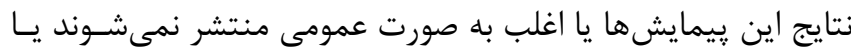
تحقيقـات انجـام شـده اطلاعـات معسدودى بــر اسـاس تعـداد زنــان سريرست خانوار با توجه به نتايج سرشمارى عمومى نفوس و مسكن

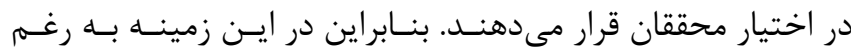

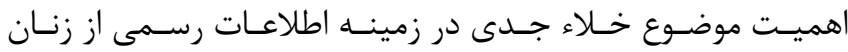
سريرست خانوار در كشور وجود دارد. از جمله تحقيقاتى كه با توجه

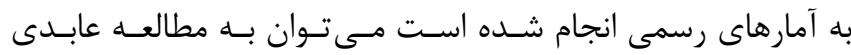

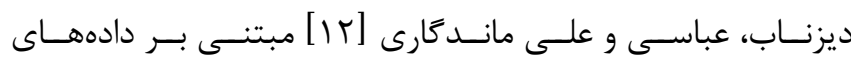

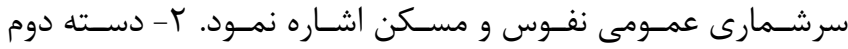

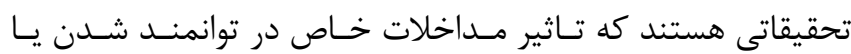
قدر تمند شدن زنان سريرست خانوار را بر رسى ميى كنند بـراى مثـال

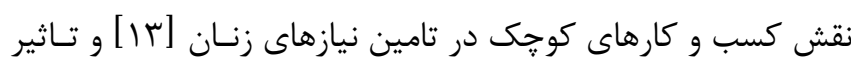

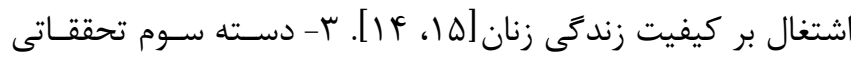

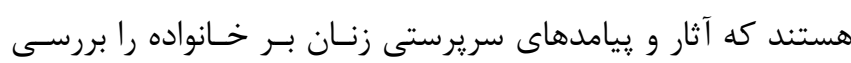

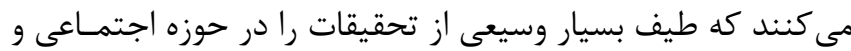

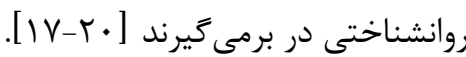

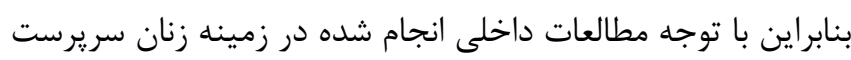

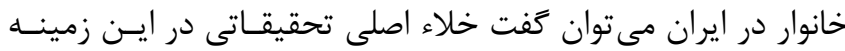

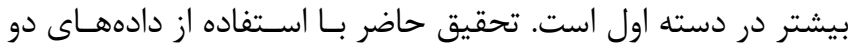

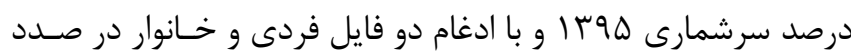

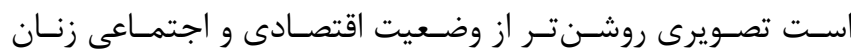

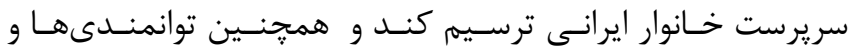

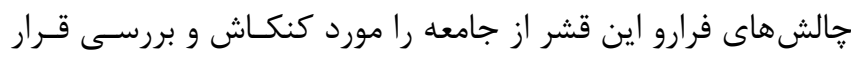

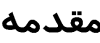

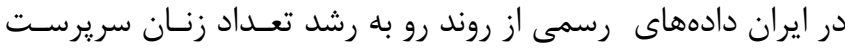

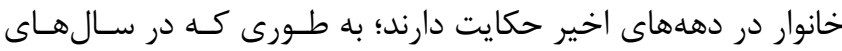

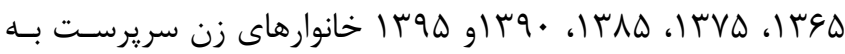

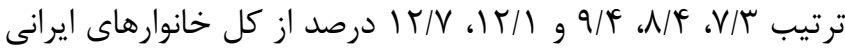

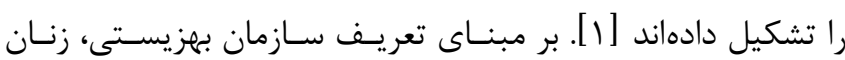

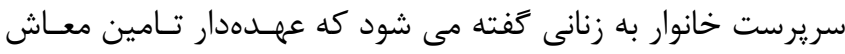
مادى و معنوى خود و اعضاى خانوار هستند. مطـابق تعريـف مركـز

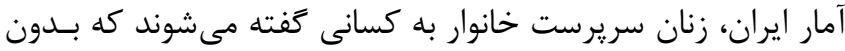

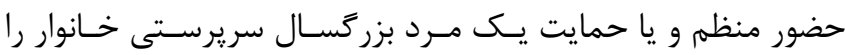
برعهده مى گيرند و مسئوليت اداره اقتصادى خانواده، تصميم گيرهاى

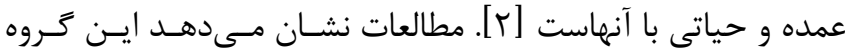
زنان به طور عمده شامل زنان بيوه، مطلقه، همسران مـردان معتـاد،

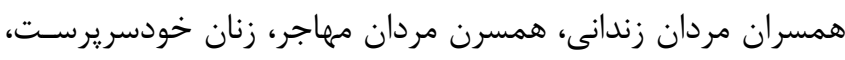

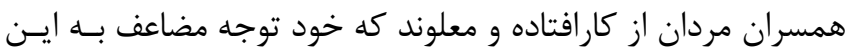
قشر از جامعه را مىطلبد [ب].

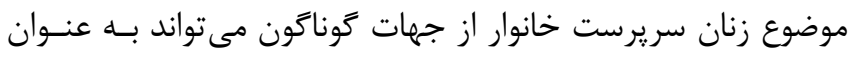

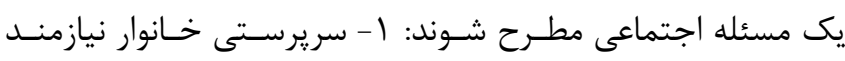
تامين منابع مالى و معنوى اعضاى خانواده است و بر اسـاس تقســيم

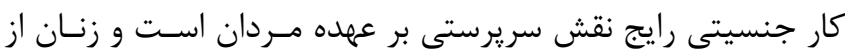

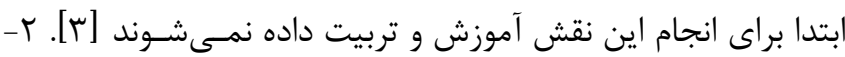

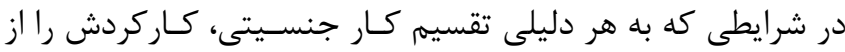

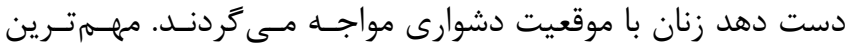

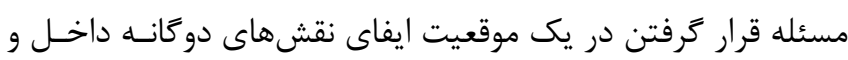

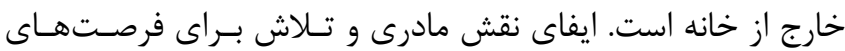

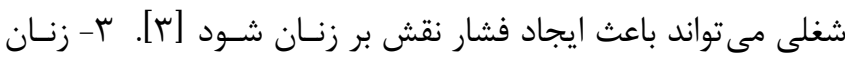

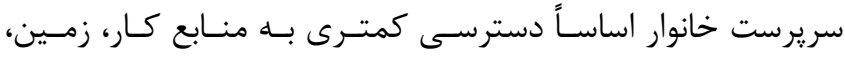

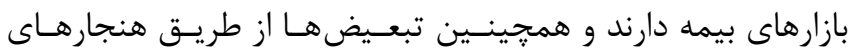

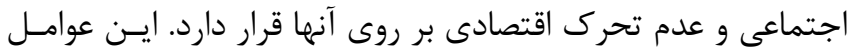

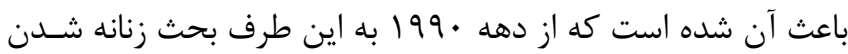

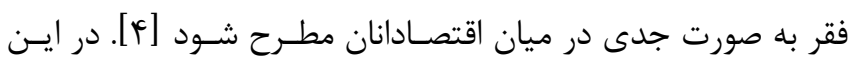

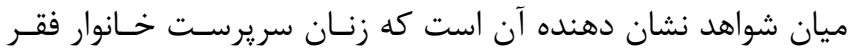

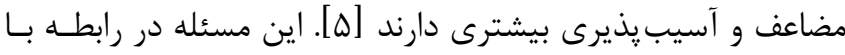

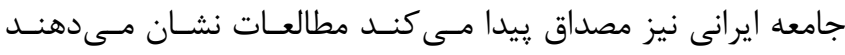

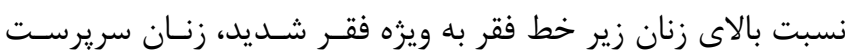

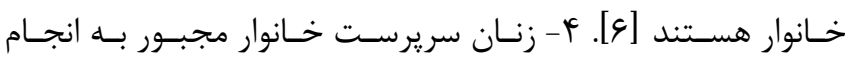


است كه IT/V درصد خانوارهاى ايرانى زن سريرست هستند تقريبـاً

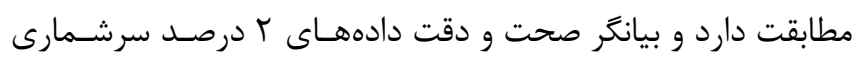

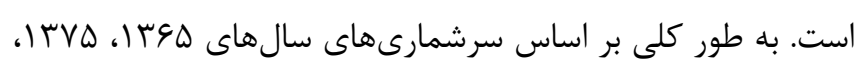

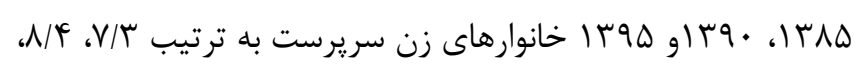

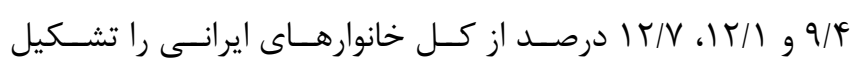

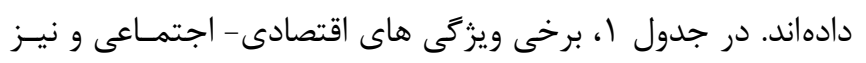

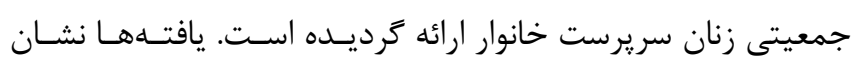

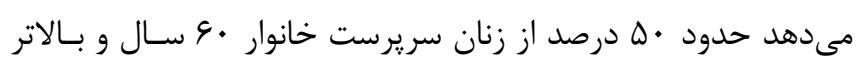

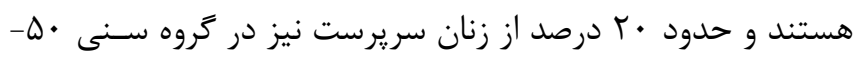

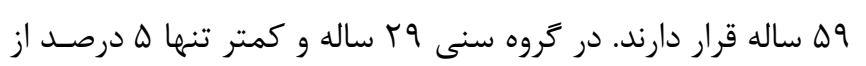

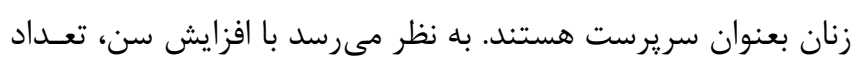

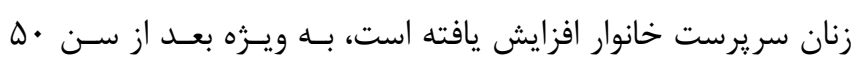

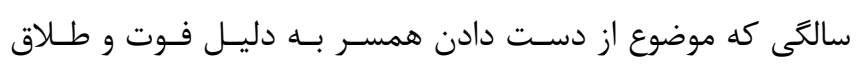

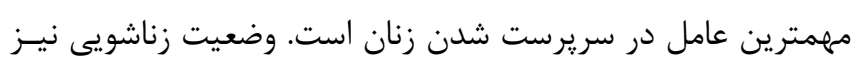

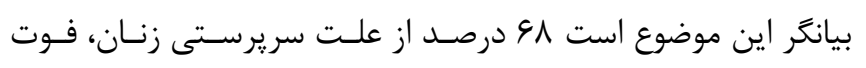

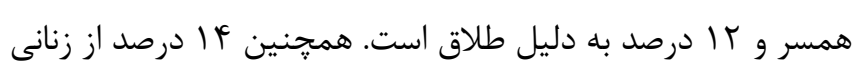

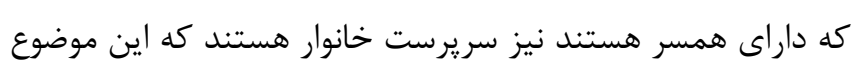

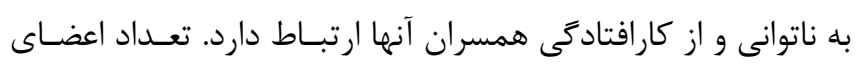

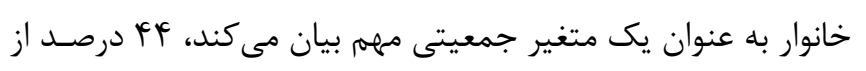

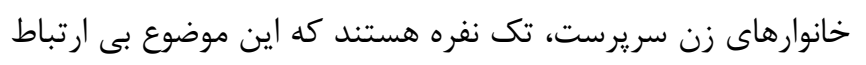

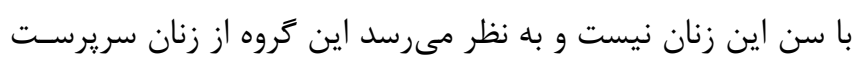

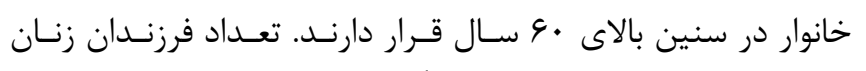

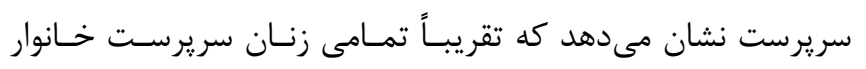

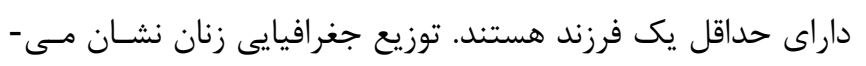

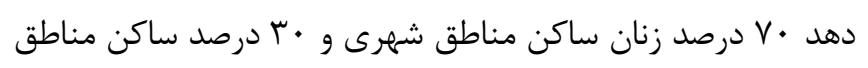

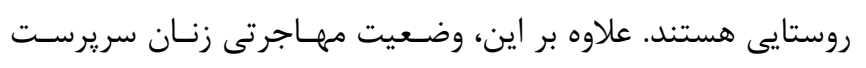

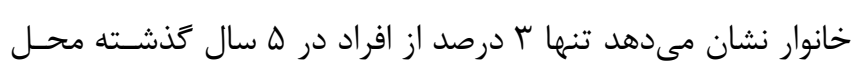

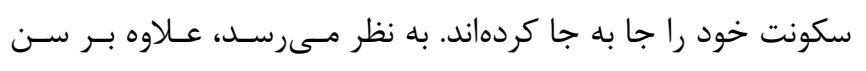

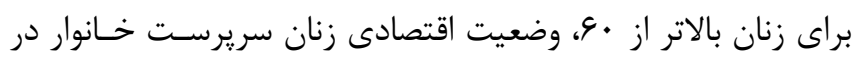

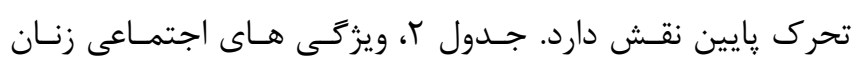

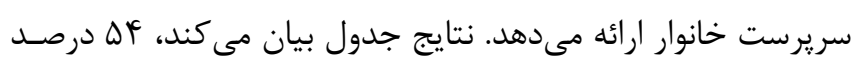

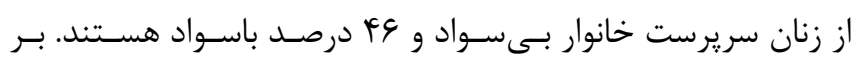

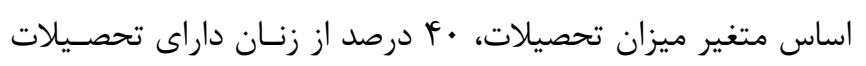

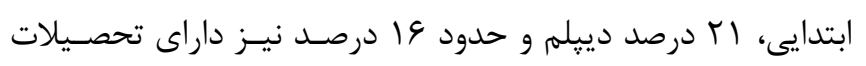

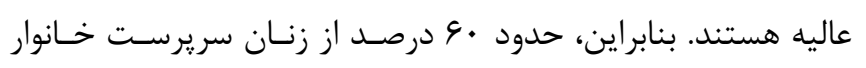
داراى تحصيلاتى يايينتر از دييلم هستند.
دهد. در نهايت با توجه به شواهد و آمارهاى رسمى الزامات سياستى

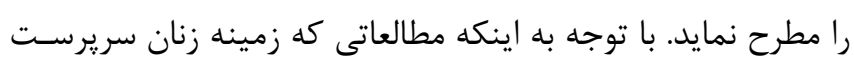

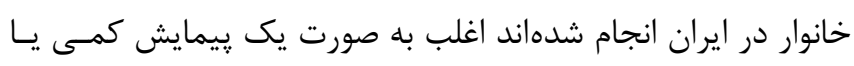

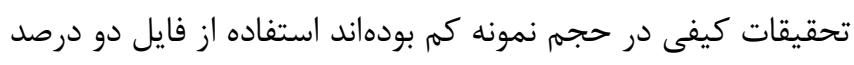

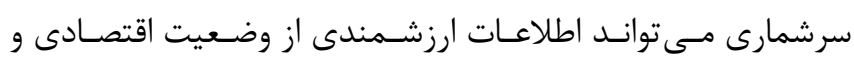

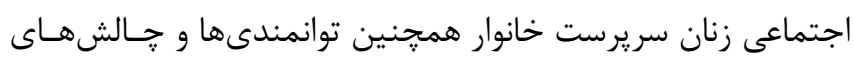

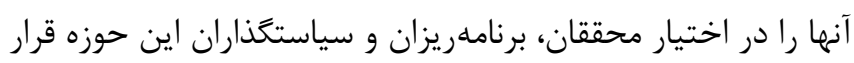

دهد.

\section{مواد و روش كار}

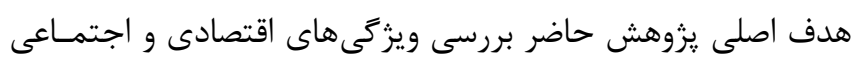

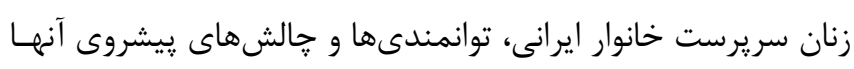

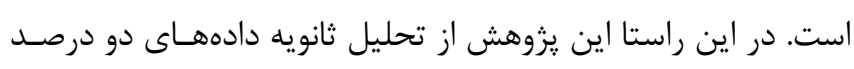

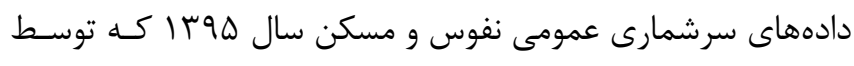

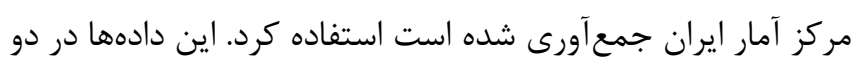

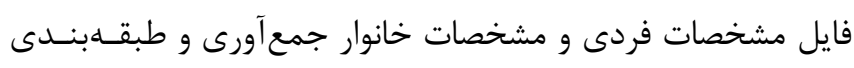

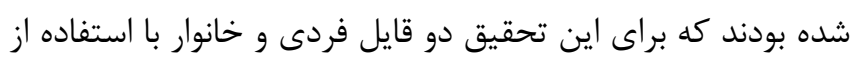

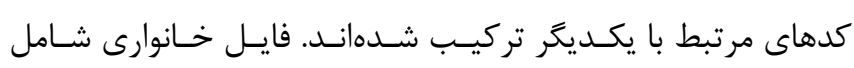

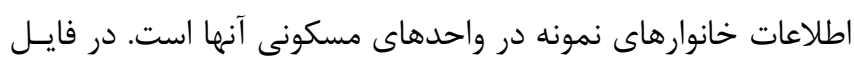

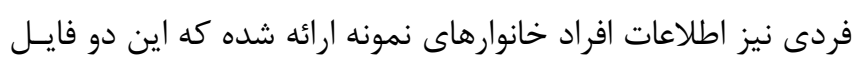

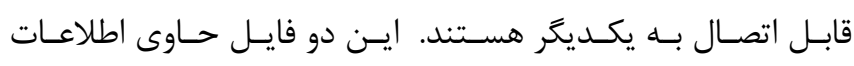

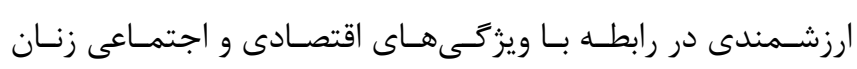

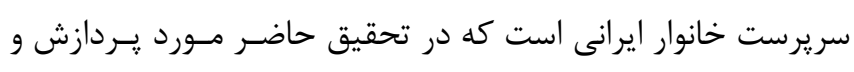

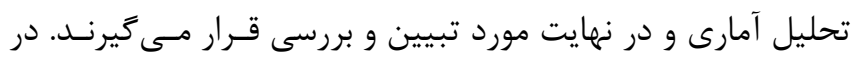

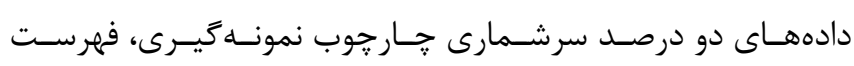

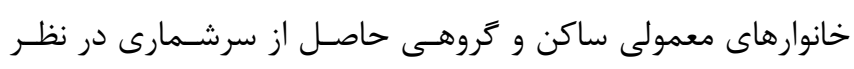

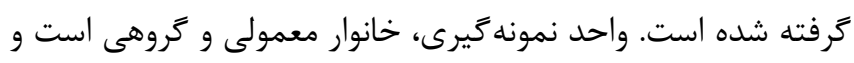

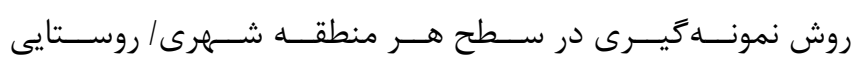

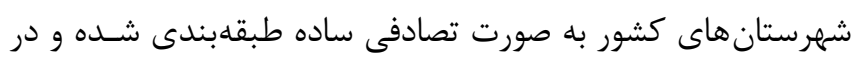

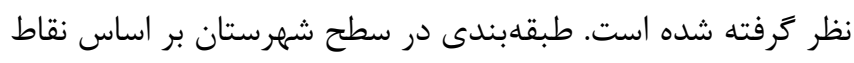

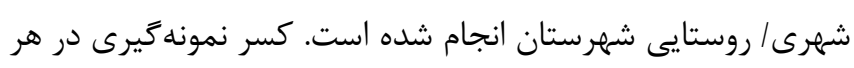
طبقه r درصد بوده است.

يافتهها

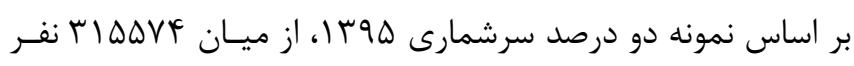

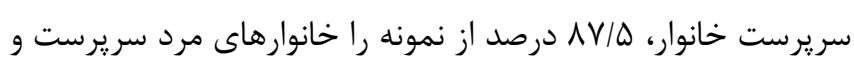

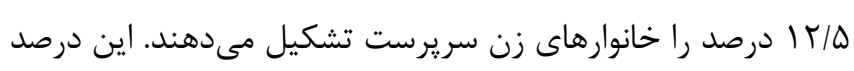

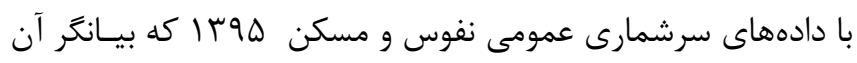


ارتباط نوع خانوار و جنسيت ارتباطى معنادار و قابل توجه است. 91

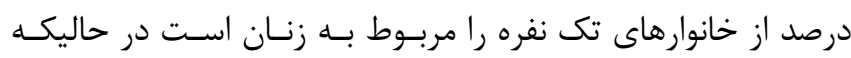

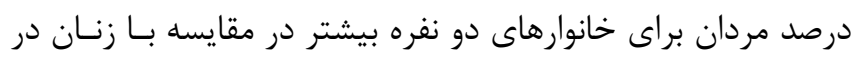

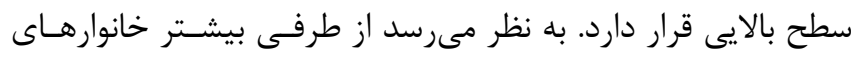

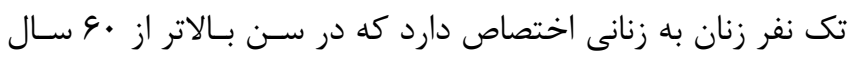

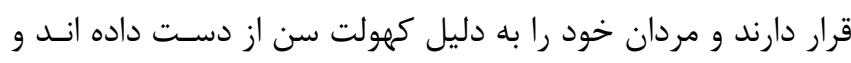

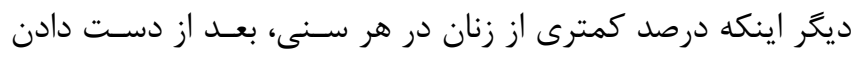

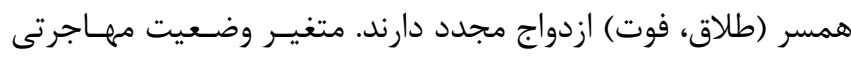

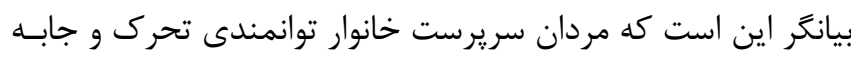

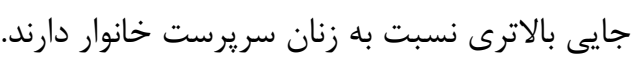

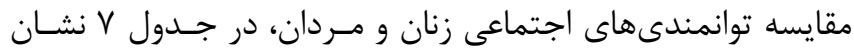
مى دهد وضعيت سواد ارتباط معنادارى با جنسيت دارد. در حان حالى كهان

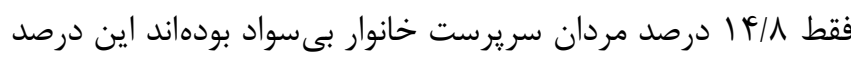

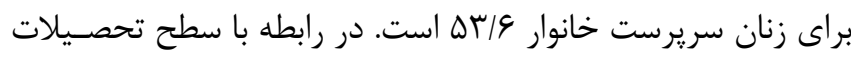

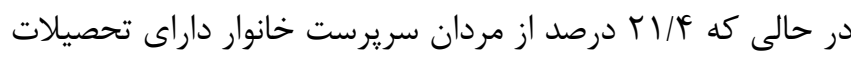

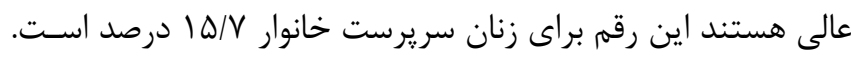

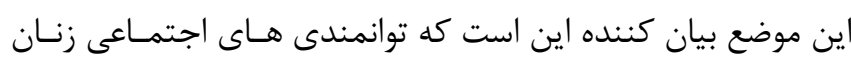

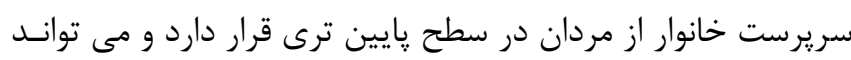

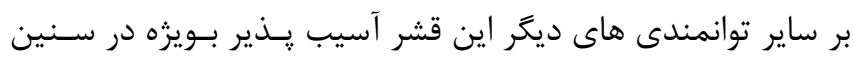

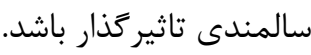

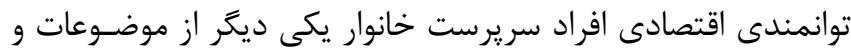

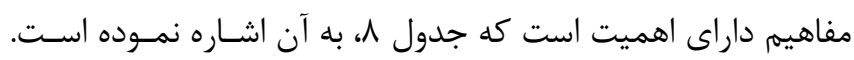

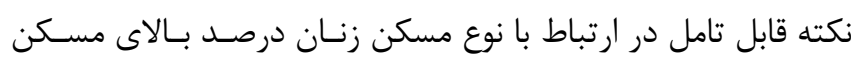

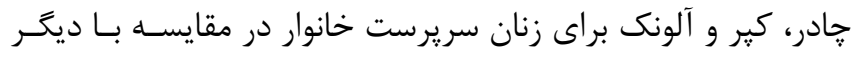

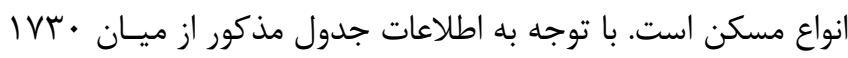

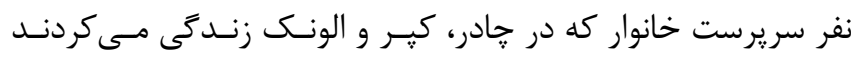

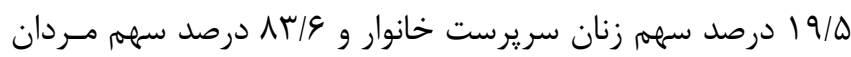

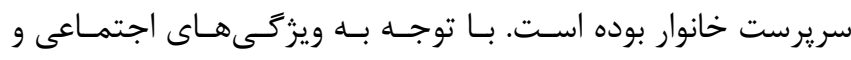

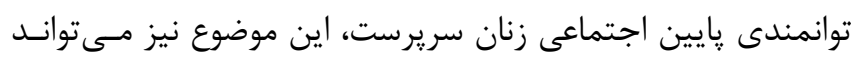
بر ناتوانى بيشتر آنان اثركذار باشدي

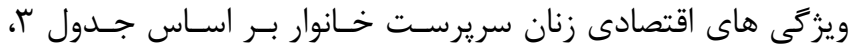

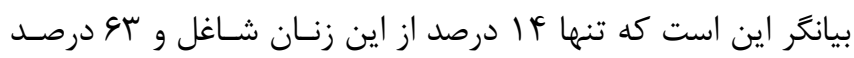

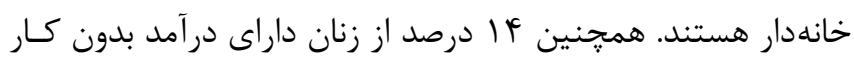

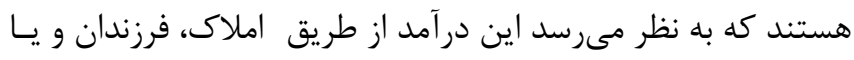

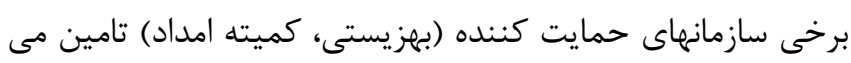

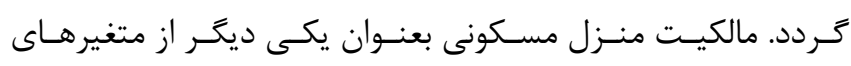

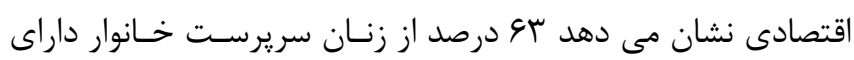

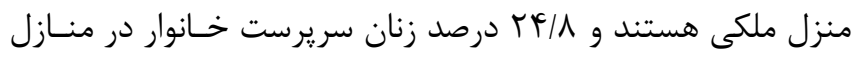

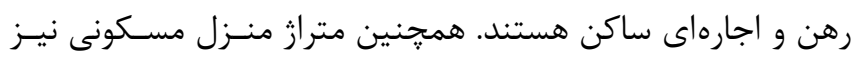

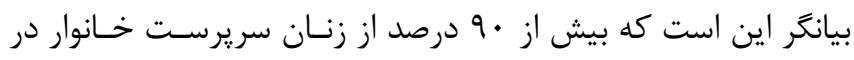

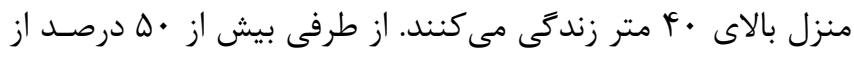

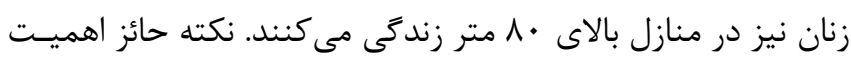

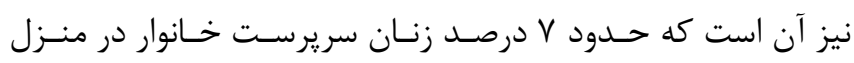

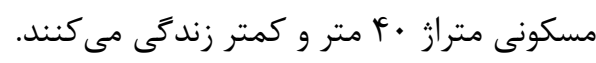

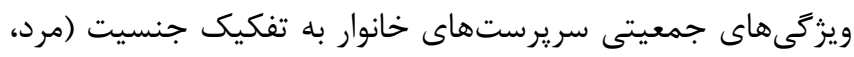

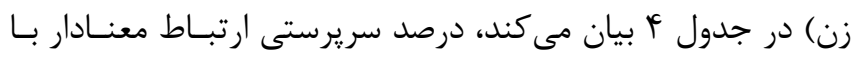

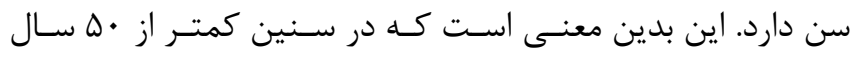

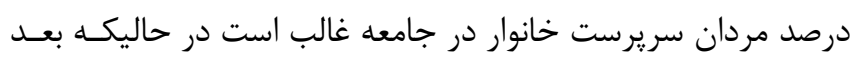

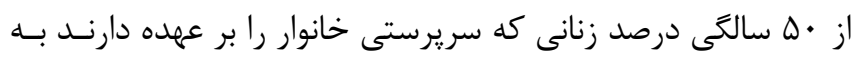

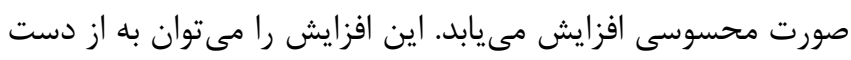

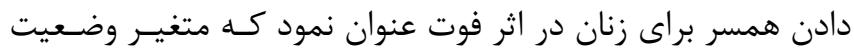

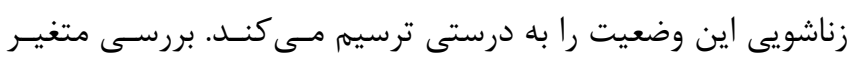

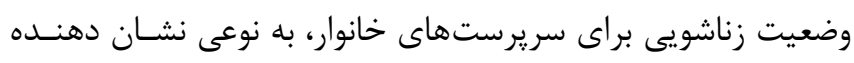

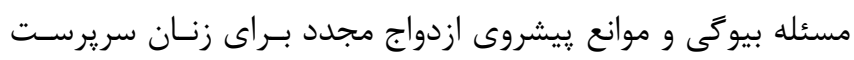

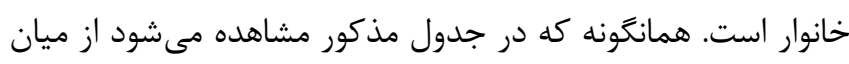

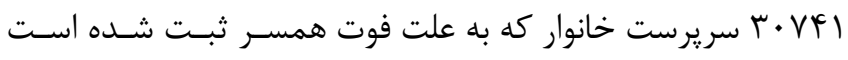

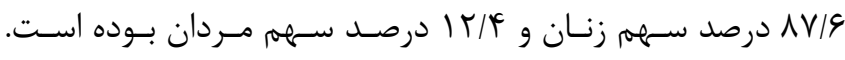

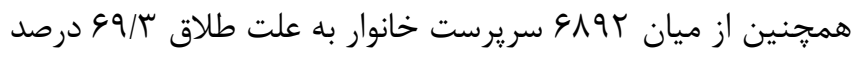

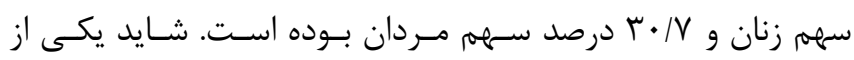
جالشهاى اساسى بيشروى زنان سريرست مســـله بيـوكى و ازدواج مجدد باشد. 
سال بيستم، شماره جهارم، مرداد ـ شهر يور ..

نشريه يثروهشده علوم بهداشتى جهاددانشگاهي

جدول ا: ويزگَى هاى جمعيتى زنان سريرست خانوار در سرشمارى هوبا

\begin{tabular}{|c|c|c|c|}
\hline درصد & تعداد اعضاى خانوار & درصد & ستغير \\
\hline fF & تك نفره & $4 / 9$ & 9ץ-• ساله \\
\hline$r E / F$ & دو نفره & $14 / 9$ & q q-_• سالد \\
\hline IV & سه نفره & $19 / 01$ & ( \\
\hline $\mathrm{V} / \mathrm{\Lambda}$ & جهار نفره & rI/qu & 99-4.9 ساله \\
\hline$r / \Lambda$ & ينج نفره و بالاتر & $r V / I T$ & ل ساله و بالاتر V. \\
\hline r१Q९ & 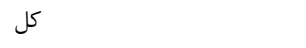 & ए৭४९ & كل \\
\hline درصد & تعداد فرزند & درصد & وضعيت زناشويى \\
\hline$\cdot / 4$ & بدون فرزند & $\mid f / f$ & داراى همسر \\
\hline$r V / T$ & ا & $9 N / 1$ & بى همسر به دليل فوت \\
\hline$T V / Q$ & r r برزند & $|r /|$ & بى همسر به دليل طلاق \\
\hline$F F / q$ & بالاتر از ه فرزند & $\Delta / r$ & هرَز ازدواج نكرده \\
\hline reqre & 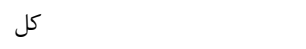 & rqpqr & كل \\
\hline درصد & وضعيت مهاجرت & درصد & توزيع جغرافيايى \\
\hline r & 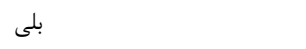 & $v \cdot / 1$ & شهر \\
\hline qV & خير - & $r q / 9$ & 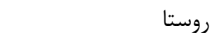 \\
\hline ५१८५q & كل - ال & r१ڤ६ & كل \\
\hline
\end{tabular}

جدول r: ويثَّى هاى اجتماعى زنان سريرست خانوار در سرشمارى هوها

\begin{tabular}{|c|c|c|c|}
\hline \multirow{2}{*}{ درصد } & \multirow{2}{*}{ متغير وضعيت سواد } & درصد & متغير تحصيلات \\
\hline & & $f \cdot / f$ & ابتدايى \\
\hline$\varphi \notin / \Gamma$ & با سواد & 1911 & راهنمايى \\
\hline$\Delta r / \varphi$ & بـ سواد & 4 & دبيرستان \\
\hline \multirow[t]{3}{*}{ rqDTा } & كل & rI & دييلم \\
\hline & & $10 / 9$ & تحصيلات عالى \\
\hline & & $|\Lambda \Lambda T|$ & كل \\
\hline
\end{tabular}

\begin{tabular}{|c|c|c|c|}
\hline \multirow[b]{2}{*}{ 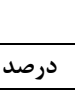 } & \multicolumn{3}{|c|}{ 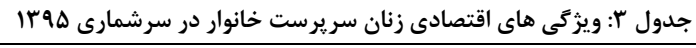 } \\
\hline & متغير & درصد & متغير \\
\hline & متراز منزل مسكونى & & وضع فعاليت \\
\hline $1 / 9$ & كمتر از بيست متر & $\mid f / F$ & 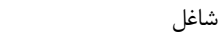 \\
\hline$\Delta / r$ & 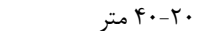 & $1 / 1$ & بيكار \\
\hline$r \varphi / 4$ & $\Lambda \cdot-\mid f_{1}$ & $1 / \pi$ & در حال تحصيل \\
\hline TF/F & 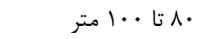 & 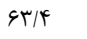 & خانه دار \\
\hline$r / / 4$ & 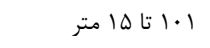 & $\mid f / T$ & دارا درامد بدون كار \\
\hline $1 \cdot 19$ & 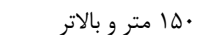 & $\Delta / \Delta$ & ساير \\
\hline \multirow[t]{2}{*}{$r q \Delta s \mu$} & جمع & $r q \Delta \Delta \uparrow$ & كل \\
\hline & 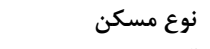 & & 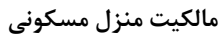 \\
\hline$r T / 9$ & آيارتمانى & $9 \pi / 1$ & 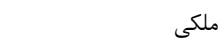 \\
\hline$V T / r$ & غير آيار تمانى & $r \Psi / \Lambda$ & رهن و اجاره \\
\hline$\cdot / 9$ & 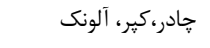 & $11 / 9$ & ساير \\
\hline$r / r$ & ساير & rVqv & 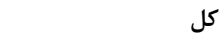 \\
\hline rqD\& & 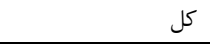 & & \\
\hline
\end{tabular}


سال بيستم، شماره جههارم، مرداد _ شهريور . If

جدول f: توزيع سريرستهاى خانوار( هر دو جنسيت) بر اساس ويثگى هاى جمعيتى

\begin{tabular}{|c|c|c|c|c|c|c|c|}
\hline \multirow{2}{*}{ كل } & \multicolumn{2}{|c|}{ سريرست خانوار } & \multirow[b]{2}{*}{ وضعيت زناشويى } & \multirow{2}{*}{ كل } & \multicolumn{2}{|c|}{ سريرست خانوار } & \multirow[b]{2}{*}{ تروه سنى } \\
\hline & 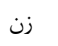 & 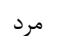 & & & 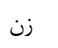 & 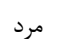 & \\
\hline rVIN.r & $r / 1$ & $9 \vee / 9$ & داراى همسر & TDATY & $\Delta / \mathcal{F}^{\mathcal{L}}$ & $94 / 9$ & كمتر از •r سال \\
\hline$r \cdot v+1$ & $\Lambda V / S$ & $\mid r / 4$ & بىهمسر بر اثر فوت & $\Lambda \Lambda \backslash \Delta \Delta$ & $\Delta / /$ & $94 / 1$ & 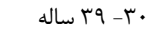 \\
\hline 4^१५ & $99 / \pi$ & $r \cdot / V$ & بى همسر بر اثر طلاق & VIN & $\Lambda / r$ & $91 / \mathrm{V}$ & ( \\
\hline$\Delta 9 \wedge 9$ & $\mathrm{rF} / \mathrm{A}$ & $9 \Delta / r$ & هرگز ازدواج نكرده & 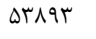 & $1 f / 4$ & $\Lambda \Delta / 9$ & 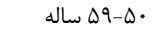 \\
\hline \multicolumn{3}{|c|}{ Phi\&Cramers $=0.813 * *$} & & TATFA & $T Y / Q$ & $V \Delta / \mathcal{F}$ & (99-9. \\
\hline كل & 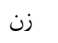 & 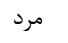 & محل سكونت & MITVE & $r y / r$ & $9 \Delta / V$ & ساله و بالاتر V. \\
\hline$T r \cdot V F \Lambda$ & $\mid r / 9$ & $\Lambda V / \mathcal{F}$ & شهر & & & & \\
\hline १FATE & $1 T / 0$ & $\Lambda \vee / \Delta$ & 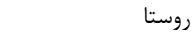 & \multicolumn{3}{|c|}{ Phi\&Cramers $=0.348 * *$} & \\
\hline \multicolumn{3}{|c|}{ Phi\&Cramers $=0.018 n s$} & & كل & 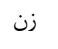 & 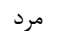 & نوع خانوار \\
\hline كل & 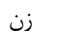 & 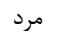 & وضعيت مهاجرت & TDFAV & $9 N / T^{4}$ & $r \mid / 9$ & تك نفره \\
\hline$r \cdot|V| 9$ & $I T / V$ & $\Lambda V / T$ & خير & SATID & $19 / \pi$ & $\Lambda r / \Lambda$ & دو نفره \\
\hline ITAFT & N/9 & $91 / 4$ & 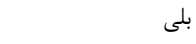 & $I V D .9 V$ & $\Delta / 9$ & $94 / 4$ & سه و جهار نفره \\
\hline \multicolumn{4}{|c|}{ Phi\&Cramers $=0.112 * *$} & $\Delta \cdot V r \omega$ & $r / \Lambda$ & $99 / 4$ & بالاتر از ينج نفره \\
\hline
\end{tabular}

ماخذ: يردازش دادههاى دو درصد سرشمارى هوس

جدول ه: توزيع سريرستهاى خانوار( هر دو جنسيت) بر اساس ويخَّىهاى جمعيتى

\begin{tabular}{|c|c|c|c|c|c|}
\hline \multirow[t]{2}{*}{ كل - ال } & \multicolumn{4}{|c|}{ وضعيت زناشويى } & \multirow{2}{*}{ كروه سنى } \\
\hline & هركز ازدواج نكرده & بدون همسر طلاق & بدون همسر فوت & داراى همسر & \\
\hline 197. & $r \cdot / 1$ & $T Y / \Lambda$ & $9 / 4$ & $f \Delta / V$ & كمتر از • بَ سال \\
\hline FDSG & $1 \cdot 11$ & $r F / r$ & $r r / V$ & $r 1 / r$ & • ץ- १ץ ساله \\
\hline$\Delta \wedge \Lambda \Lambda$ & $\Lambda / \Lambda$ & $r$ r/A & $\varphi \& / 0$ & $r \cdot / 9$ & Fq_f. \\
\hline VVrV & $\Delta / \mathcal{F}$ & $11 / r$ & $99 / 7$ & $|f /|$ & • • - \\
\hline$\Lambda 99 \Lambda$ & $r / T$ & $r / 9$ & $\wedge \& / 9$ & $V / V$ & .99-9 ساله. \\
\hline $1 \cdot V 14$ & $\cdot / 1$ & $1 / 4$ & $94 / 5$ & $r / V$ & • V ساله و بالاتر \\
\hline
\end{tabular}

ماخذ: يردازش دادههاى دو درصد سرشمارى ه9؟1

جدول \&: توزيع سريرستهاى خانوار( هر دو جنس) بر اساس ويزگى هاى جمعيتى

\begin{tabular}{|c|c|c|c|c|c|}
\hline \multirow[t]{2}{*}{ كل } & \multicolumn{3}{|c|}{ اعضاى خانوار } & \multirow[b]{2}{*}{ تك نفره } & \multirow[b]{3}{*}{ كمتر از •r سال } \\
\hline & ه نفر به بالا & r أ نفره & دو نفره & & \\
\hline 1945 & $1 / 0$ & $r \cdot / q$ & (T/ו & $F F / D$ & \\
\hline fove & $9 / 0$ & $r \Delta / 9$ & rT/F & $r \Delta / \Delta$ & 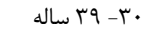 \\
\hline$\Delta \wedge 91$ & $V / q$ & $f I / T$ & $r q / r$ & $r I / V$ & ( \\
\hline VYFa & $V / 1$ & $\mathrm{HI/A}$ & $r q / \Delta$ & 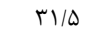 & • • • • \\
\hline$\wedge \notin \vee 9$ & $F / V$ & $T r / \Lambda$ & $T V / F$ & is & (99-9. \\
\hline $1 \cdot V r q$ & $1 / 4$ & $\Lambda / \mathcal{F}$ & 11 & $V T / T$ & ساله و بالاتر V. \\
\hline \multicolumn{4}{|c|}{ Kendal tau $c=-0.376$} & & \\
\hline
\end{tabular}


سال بيستم، شماره جهارم، مرداد ـ شهر يور If..

نشريه يروهشكده علوم بهداشتى جهادانشگاهى

جدول У:توزيع سريرستهاى خانوار ( هر دو جنسيت) بر اساس توانمندى اجتماعى

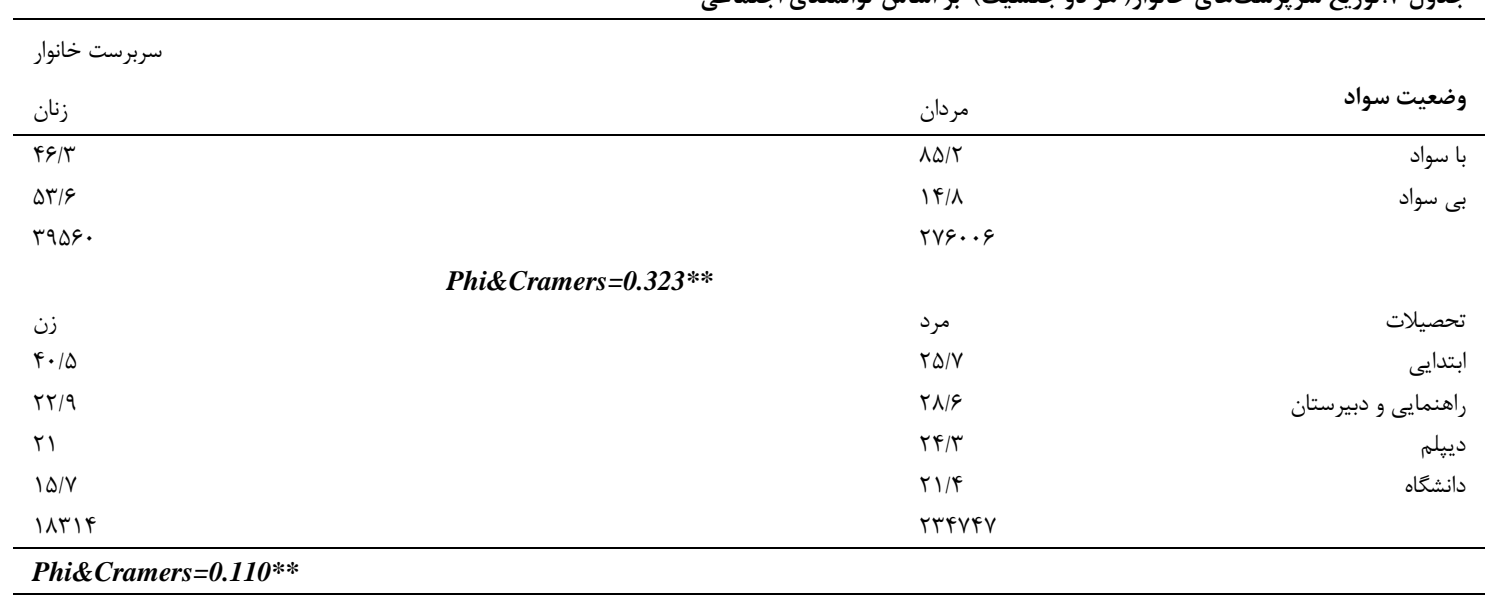

ماخذ: يردازش دادههاى دو درصد سرشمارى ه9

جدول ^: توزيع سريرستهاى خانوار( هر دو جنس) بر اساس توانمندى اقتصادى

\begin{tabular}{|c|c|c|c|}
\hline \multirow{2}{*}{ كل } & \multicolumn{2}{|c|}{ سربرست خانوار } & \multirow[b]{2}{*}{ نوع مسكن } \\
\hline & 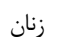 & 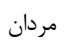 & \\
\hline$\Lambda \Gamma \Delta \Delta \mid$ & $11 / r$ & $\Lambda N / \Lambda$ & آيارتمانى \\
\hline TrTENG & $1 r / 9$ & $\wedge \vee / 1$ & غير آيار تمانى \\
\hline IVr. & $19 / 0$ & $\Lambda \cdot / \Delta$ & جادر،كير، آلونك \\
\hline \multirow[t]{2}{*}{$v \varepsilon \cdot \Delta$} & $19 / 4$ & $\wedge r / 9$ & ساير \\
\hline & \multicolumn{2}{|c|}{ Phi\&Cramers $=0.133 * *$} & \\
\hline كل & 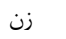 & 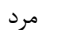 & 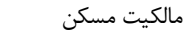 \\
\hline I9fIV. & $1 T / r$ & $\Lambda \vee / \vee$ & ملكى \\
\hline NFAN & $11 / 1$ & $1 \mathrm{~N} / \mathrm{q}$ & رهن و اجاره \\
\hline \multirow[t]{2}{*}{ 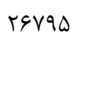 } & $19 / 1$ & $\Lambda r / r$ & ساير \\
\hline & \multicolumn{2}{|c|}{ Phi\&Cramers $=0.145 *$} & \\
\hline 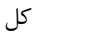 & 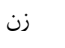 & 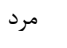 & وضع فعاليت \\
\hline TIVATF & $T / 9$ & $9 \vee / \uparrow$ & شاغل \\
\hline १९६. & $F / Q$ & $9 \Delta / \Delta$ & بيكار \\
\hline FQIQ & $1 / 1$ & $1 N / 9$ & در حال تحصيل \\
\hline rat.. & $9 \Delta / r$ & $F / V$ & خانه دار \\
\hline F.rTr & $1 r / 9$ & $\wedge \notin / 1$ & داراى دارمد بدون كار \\
\hline $19 \Delta \wedge 1$ & $1 \pi / 1$ & $\wedge \varepsilon / 9$ & ساير \\
\hline \multicolumn{3}{|c|}{ Phi\&Cramers $=0.765^{* *}$} & \\
\hline
\end{tabular}

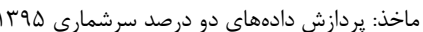

اقتصادى و سلامت نيازمند توجه هســنـد. هـــف از مطالعـه حاضـر

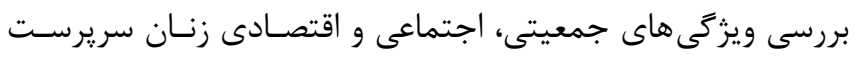

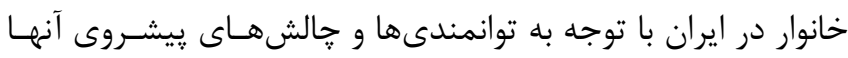

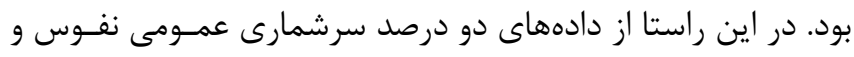

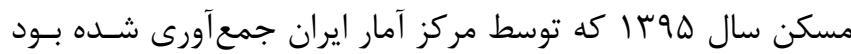

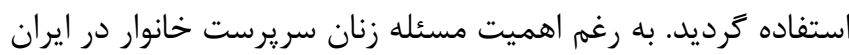

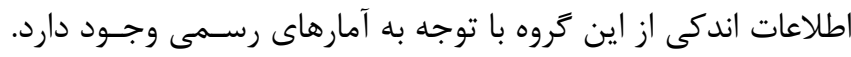

\section{بحث و نتيجه كَيرى}

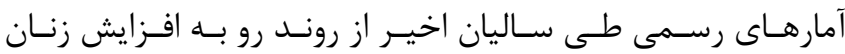

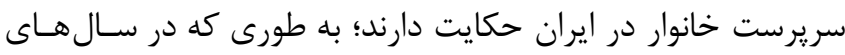

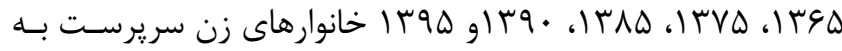

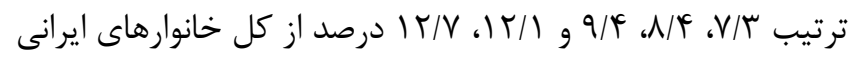

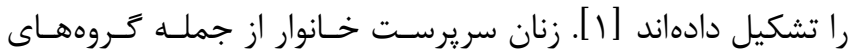

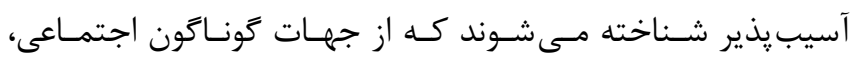




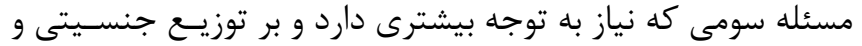

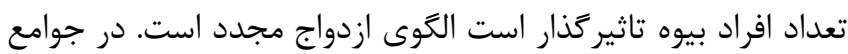

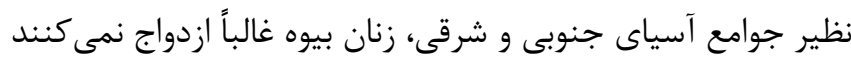

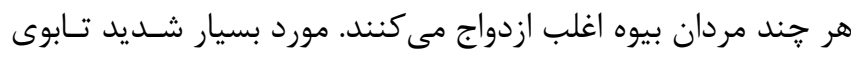

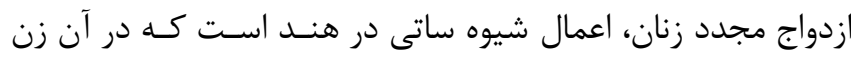

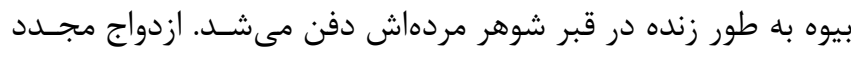

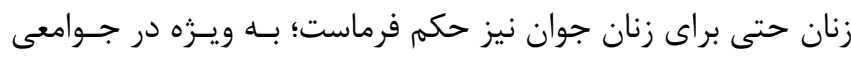

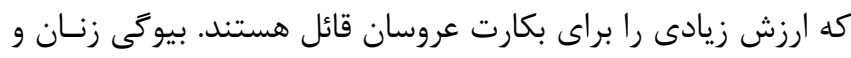

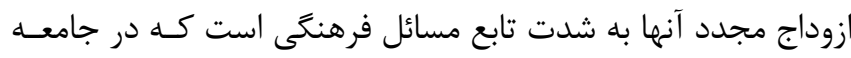

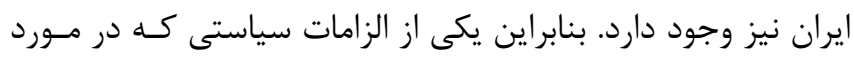

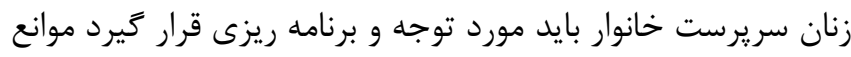

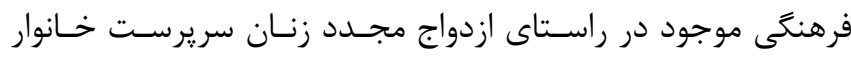

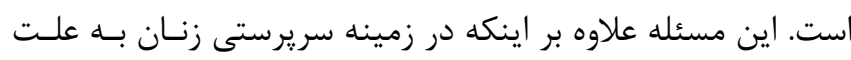

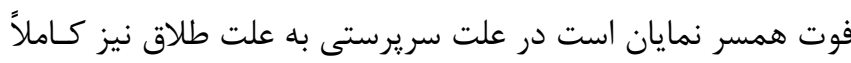

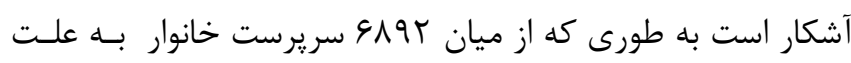

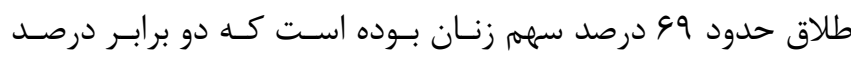
مردان بوده است. جالش ديكر بِيشرو زنان سريرست خانوار كه به نظر مىرسد با توجه

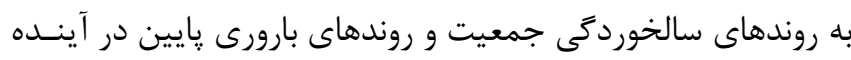

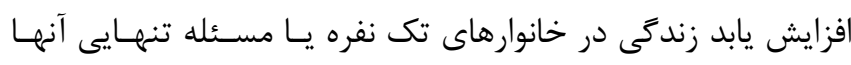

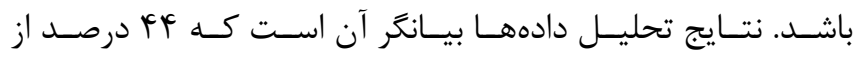

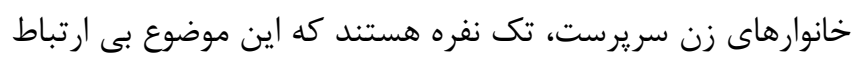

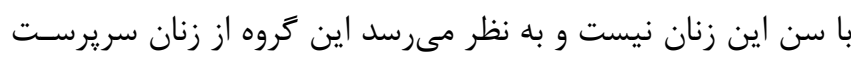

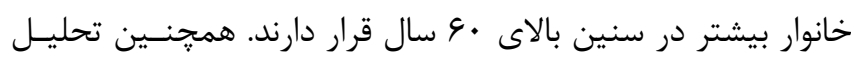

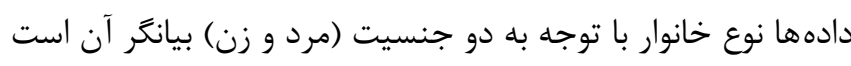

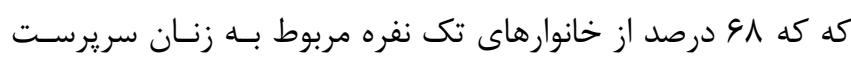

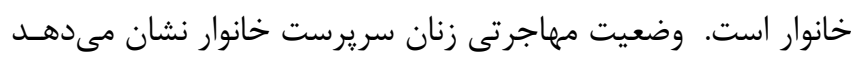

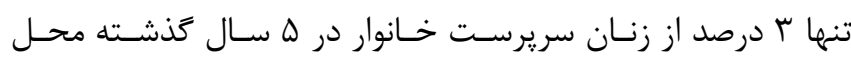

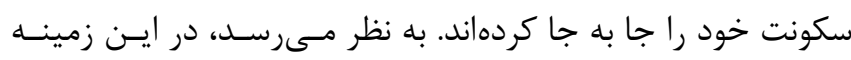

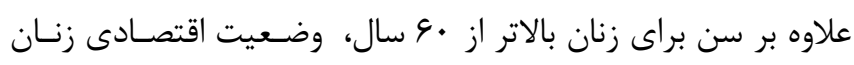

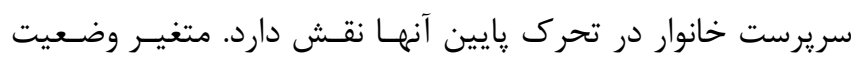

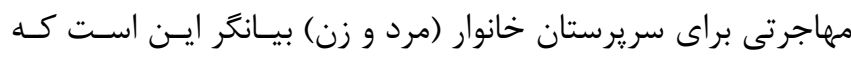

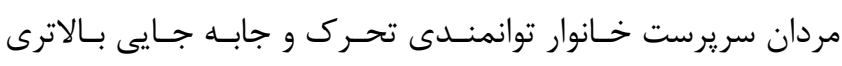
نسبت به زنان سريرست خانوار دارند.

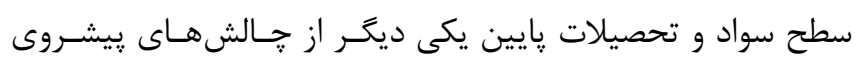

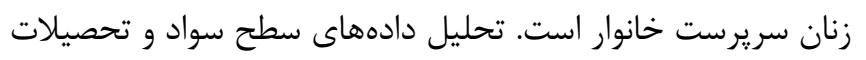

دادههــاى دو درصـد سرشـمارى بــا در اختيــار كذاشــن دو فايـلـ

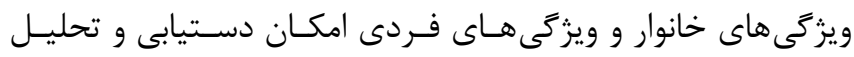

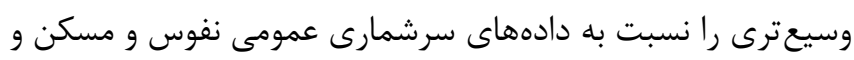

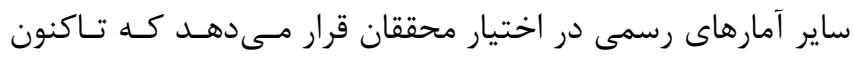

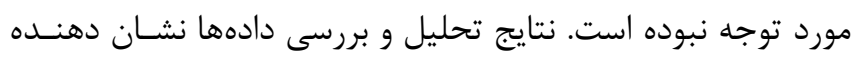

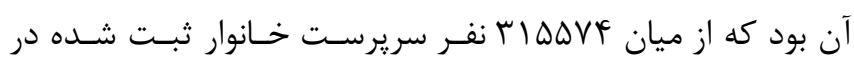

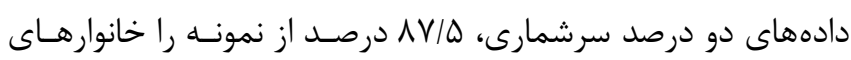

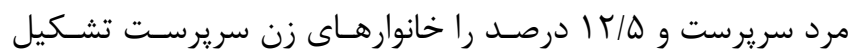

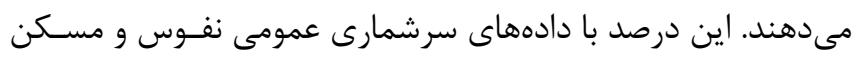

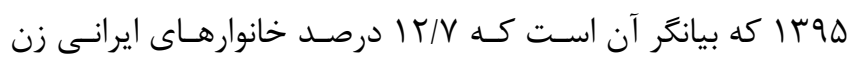

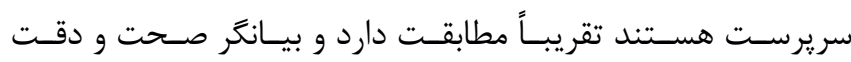

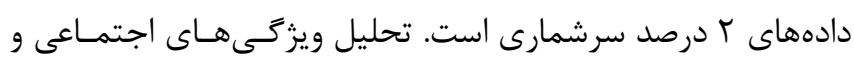

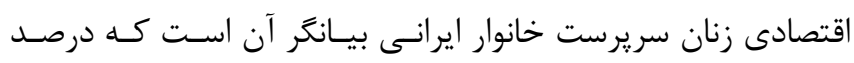

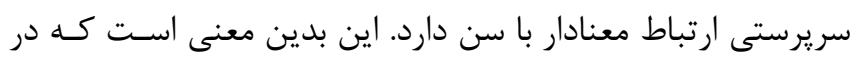

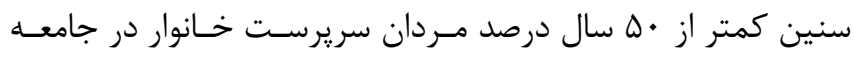

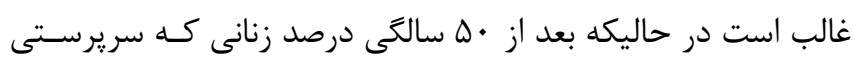

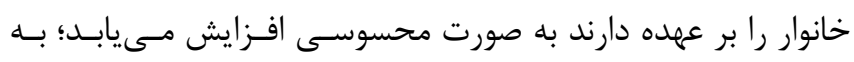

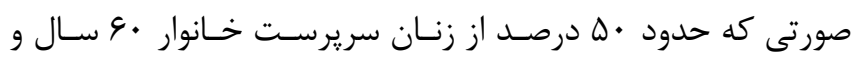

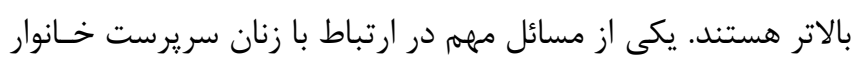

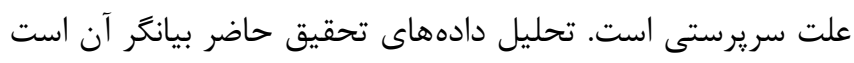

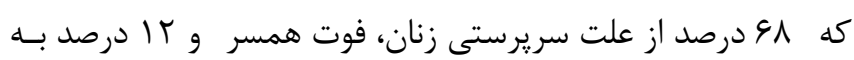

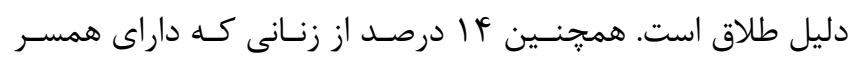

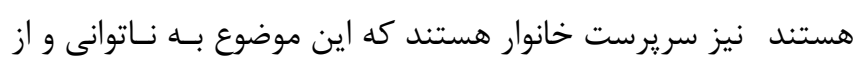

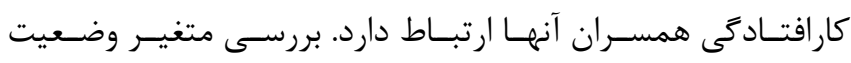

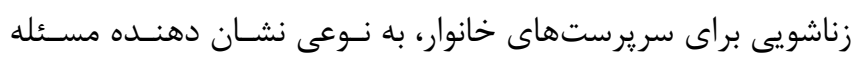

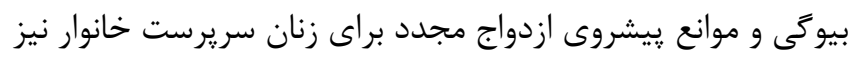

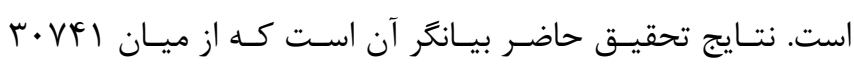

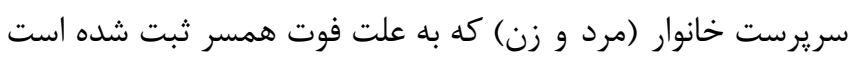

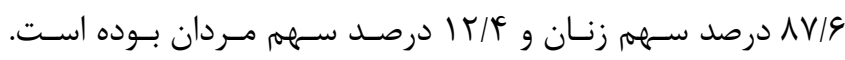

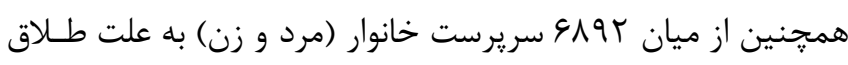

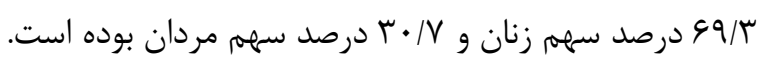

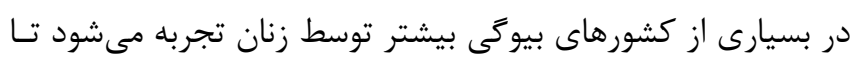

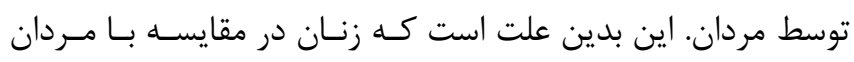

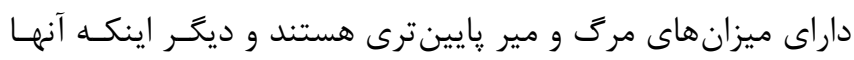

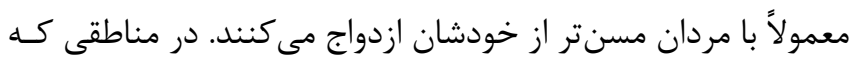

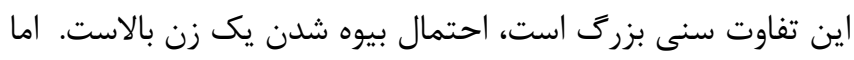




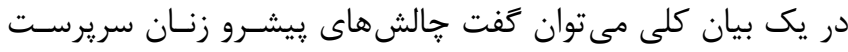

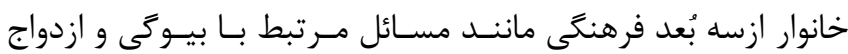

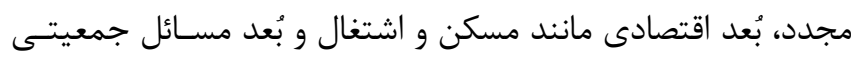

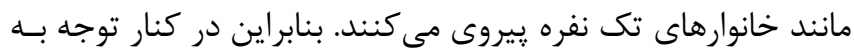

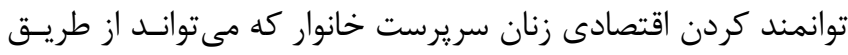

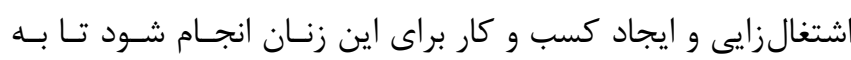

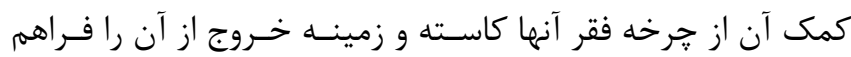

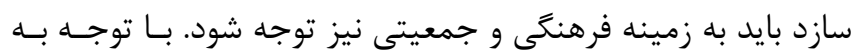

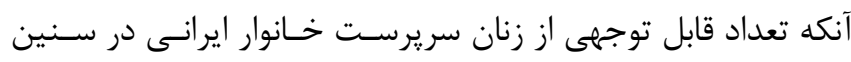

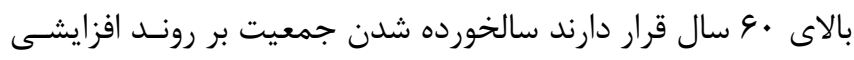

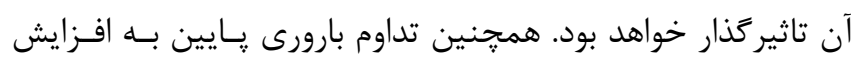

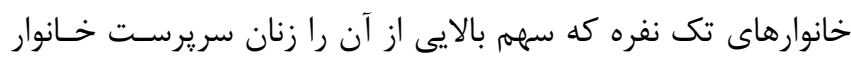

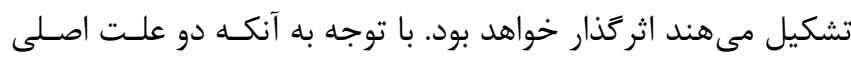

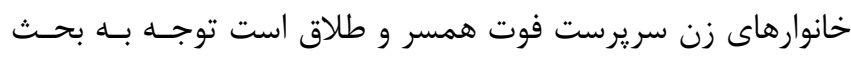

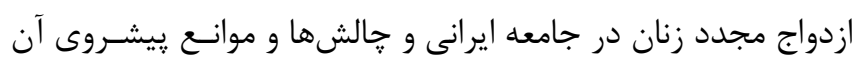
بيش از هر زمانى لازم و ضرورى مجى مدآيد.

\section{سهم نويسند}

احمد دراهكى: طراحى و نتارش مقاله، تحليل دادها، نتيجه كيرى و نوايسنان

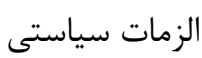

رضا نوبخت: طراحى مقاله، يرداش دادهــا، نتيجــــيــــى و الزمـات سياستى

\section{منابع}

1. Statistical Center of Iran. Detailed results of population and housing censuses from 1986 to 2016 https://www.amar.org.ir/ [ Persian]

2. Momenzadeh N. A comparative analysis of Women -headed households. Economic Journal 2014; 3: 12095 [Persian]

3. Amadnia S, Ghlibaf kamel A. Women-Headed Households in Tehran: A Qualitative Study of Their Experiences, Challenges and Capacities. refahj 2017; 17:103-136 [Persian]

4. Chant S. Gender, generation and poverty: exploring the Feminization of poverty in Africa, Asia and Latin America. $1^{\text {st }}$ Edition. Edward Elgar Publishing: Uk, 2007
براى سريرستان خانوار بيانكر آن اسـت كـهـ وضـعيت سـواد ارتبــاط

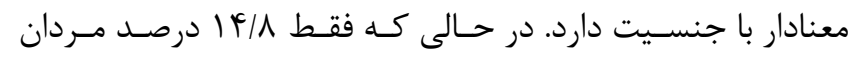

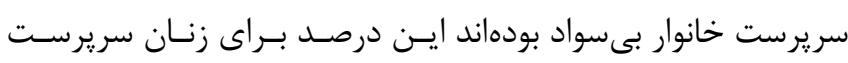
خانوار درصد از مردان سريرست خانوار داراى تحصيلات عالى هستند ايـن إنـ

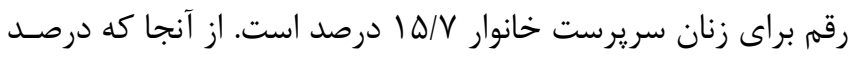
قابل توجهى از زنان سريرست خانوار ايرانى در سنين بالاى • ع سال

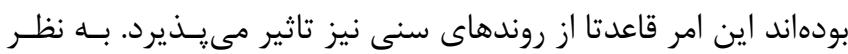

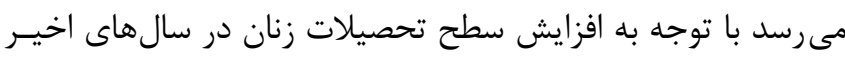

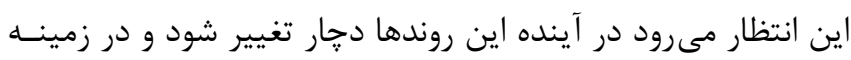
تحصيلات بر توانمندى زنان سريرست خانوار افـزده شـود. ايــن امـر

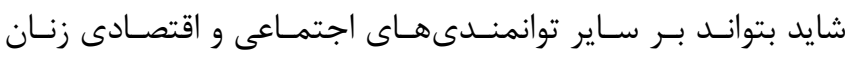
سريرست خانوار تاثير كذار باشد.

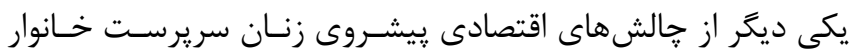

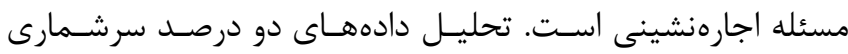

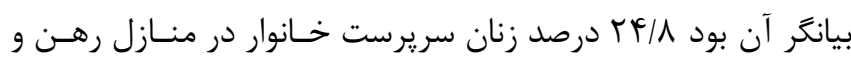

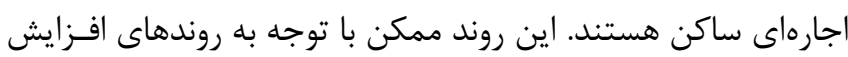

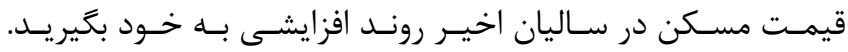

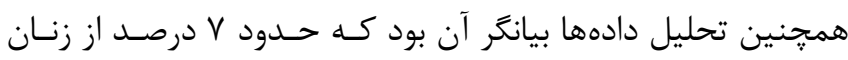

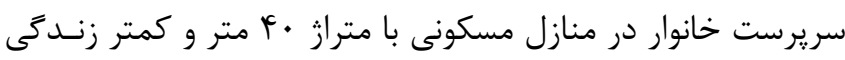

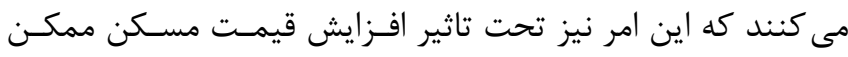
است در ساليان اخير و ييشرو روند افزايشى به خون خود بكيرد.

5. Buvinic, M. and G.R. Gupta. Female-Headed Households and Female-Maintained Families: Are They Worth Targeting to Reduce Povert in Developing Countries?. Economic Development and Cultural Change 1997; 45: 259 - 280

6. Shaditalab J, Graynejad A. Poverty of women heads of households, Women's Research Journal 2004; 2: 70-49 [Persian]

7. Connell J, Brazier J, O'Cathain A, Lloyd-Jones M, Paisley S. Quality of life of people with mental health problems: a synthesis of qualitative research. Health and Quality of Life Outcomes 2007; 10:138

8. Ozawa MN, Lee Y, Wang KY-T. Economic conditions of female-headed households in Taiwan in 
comparison with the United States and Sweden. Journal of Comparative Social Welfare 2007; 27:63-74

9. Burstrom B, Whitehead M, Clayton S, Fritzell S, Vannoni F, Costa G. Health inequalities between lone and couple mothers and policy under different welfare regimes-the example of Italy, Sweden and Britain. Social Science \& Medicine 2010; 70:912-20

10. Attree P. Low-income mothers, nutrition and health: a systematic review of qualitative evidence. Maternal \& Child Nutrition 2005; 1:227-40

11. Stewart-Withers R. Contesting a Third World development category: Female-headed households in Samoa. Women's Studies International Forum 2011; 34171-84

12. Abedi Diznab M, Abbasi M, Ali Mandegari M. A Comparative Study of the Characteristics of Female and Male Heads of Households in Urban and Rural Areas (1395 Census of Iran). Iranian Journal of Official Statistics Studies 2018; 29:95-113 [Persian]

13. Saadi H. The Role of Small Businesses in Meeting the Basic Needs of Women Heads of Rural Households in Hamadan Province, Iranian Journal of Agricultural Economics and Development Research 2012; 44: 282-271[Persian]

14. Edrisi $F$, Hatemvand $Z$. Investigating the Impact Mechanism of Employment on the Quality of Life of Women Heads of Household, Social Sciences Research Journal 2012; 4: 127-97 [Persian]

15. Kavand H, Avazalipour M S, Zandi F, Damankeshideh M. The Role of Gender in Economic Participation and the Key Women Employment
Factors: a Case of Iran. Journal of Economic Policy. 2010; 6: 189-213 [Persian]

16. Balali Meybodi F, Hosseinpour M, Mahmoudi M, Mehrbakh SH, Haji Maghsoudi S. Prevalence of depression in Women -headed households under the auspices of the Kerman Relief Committee, Dena Jurnal 2010; 5: 17-11[ Persian]

17. Irvani, M R. Comparative study of mental health of working women heads of households and ordinary working women in Sari in 2009, The Women and Family Cultural-Educational Journal 2011; 5: 145-117 [Persian]

18. Jamali $M$, Sepah Mansor $M$, fallahian $M$. Comparative study of psychological well-being of female heads of house hold \& women in male headed households in Tehran. Women in Development and Politics 2013; 11: 542-531 [Persian]

19. Hosseini $S$ A, Foruzan A, Amirfaryar $M$. Assessing the mental health of women heads of households under the auspices of the Welfare Organization of Tehran. Social Research Journal 2009; 2: 137-117 [Persian]

20. Yahyazadeh H, Ramezani M (1392). Social health and social factors affecting it Case study: Women heads of households in Qorveh, Journal of Welfare Planning and Social Development 2013; 16: 103-68 [Persian] 